\title{
The Influence of English Learning Attrition on Language Learning Strategies
}

\author{
Mei Zhang \\ Basic Courses Teaching Department, \\ The Armed Police Academy \\ Langfang, Hebei Province, China 065000 \\ E-mail:705145319@qq.com
}

\begin{abstract}
The article aims to investigate the influence of the English learning attrition on language learning strategies. The data show the three kinds of strategies are reduced with the attrition time.
\end{abstract}

Keywords-English learning attrition; language learning strategies; attrition time

\section{INTRODUCTION}

English learning attrition means learners less (or never) use English after their formal school education ends. A number of studies have indicated that language knowledge and language skills are affected by language attrition (Weltens, 1987; Tomiyama, 1999). Learning strategy is "the act of learning in order to make language learning more successful, more autonomous, more enjoyable," (Oxford, 1990). Up to now, the articles on the relationship between the English learning attrition and language learning strategies have not been published. So this paper will discuss the topic.

\section{RESEARCH METHODOLOGY}

\section{A. Questions}

1) What language learning strategies do subjects employ in learning English?

2) Does the attrition time affect the subjects' choice of language learning strategies?

3) How does the attrition time influence the subjects, strategy use?

\section{B. Instruments}

The questionnaire used for the current study contains two sections. Section one is the Background Questionnaire which includes the attrition time. Section two is on English learning strategy use. Oxford's Strategy Inventory for Language Learning (SILL, Oxford, 1990) is used as the main data collection instrument. The SILL questionnaire consists of six categories. They are Memory strategies, Cognitive strategies, Compensation strategies, Metacognitive strategies, Affective strategies and Social strategies. A five-point scale (Likert Scale) is employed to assess how true the statement is. As for the answer to each statement, students should write down any one of the number from 1 to 5 , among which 1 means "never or almost never true of me", 2 means "usually not true of me", 3 means "somewhat true of me", 4 means "usually true of me", and 5 means "always or almost always true of me". The SPSS is used to process the data.

\section{Participants}

Two hundred and thirty-seven students are chosen as subjects. They are all freshmen and just start their college life in September. Before they are enrolled, their English learning have been stopped for a period of time.

\section{Data collection and Analysis}

The English teachers distribute questionnaires to the students in English classes. Necessary explanations of the questionnaires are given before the students are asked to finish the questionnaires. After the data are collected, they are examined individually. 237 students return valid questionnaires. 5 students do not finish their questionnaires and their feedback is considered invalid. These incomplete questionnaires were discarded. The data from 232 usable questionnaires are coded for statistical analys is to answer the research questions indicated above. The statistical package for the Social Sciences (SPSS) are used for the statistical analysis of the data. The statistical process include: (1) descriptive statistics such as calculating the mean and standard deviation of each learning strategies to get the overall learning strategies tendency of the students; 2) correlation analysis investigates whether there is a relationship between attrition time and the choice of English strategies; (3) simple regression analys is investigates how does the attrition time affect the choice of English learning strategies.

\section{RESULTS AND DISCUSSION}

\section{A. Frequencies for strategy use}

In this study, all the mean scores of the six learning strategies are lower than 3, which means the participants use learning strategies less than half of the time. Compensation Strategies and Metacognitive Strategies fall into medium frequency since their mean scores are 2.7 and 2.5, which indicates the subjects "sometimes" use the two learning strategies. The other four learning strategies fall into low frequency since their mean scores are lower than 2.5, which means the subjects generally don't use the four learning strategies. From the above analysis. it can be seen that the level of subjects' awareness of learning strategies is low, and they use few learning strategies in their language learning. 


\begin{tabular}{|l|l|l|}
\hline \multicolumn{1}{|c|}{ Strategies } & Mean & Std. De viation \\
\hline Memory & 2.3 & .63 \\
\hline Cognitive & 2.4 & .62 \\
\hline Compensation & 2.7 & .75 \\
\hline Met acognitive & 2.5 & .76 \\
\hline Affect ive & 2.4 & .77 \\
\hline Social & 2.5 & .86 \\
\hline
\end{tabular}

B. Correlations between the language leaming strategies and the attrition time

Correlation analysis is used to show a number of relationships between difference variables. As shown in Table 2, the attrition time has a negative influence on the six learning strategies. At the 0.01 level, significant correlation are found. Memory Strategies $(r=-0.182, p=0.005)$. Cognitive Strategies $(r=-0.265, p=0.000)$, Compensation Strategies ( $r=-$ $0.293, \mathrm{p}=0.000$ ) have significant but negative correlations with the attrition time. According to Oxford's (1990) classification of language learning strategies, Memory Strategies, Cognitive Strategies and Compensation Strategies are direct learning strategies. That is, there is a significant negative correlation between the attrition time and the direct learning strategies at the 0.01 level. This indicates that longer the subjects stop English learning, the worse they use the direct strategies. Metacognitive Strategies, Affective Strategies and Social Strategies are the indirect strategies. At the 0.05 and 0.01 level, no significant correlations are found in Metocognitive Strategies $(r=-0.079, p=0.224)$, Affective Strategies $(\mathrm{r}=-0.099, \mathrm{p}=0.129)$ and Social Strategies $(\mathrm{r}=-0.105$, $\mathrm{p}=0.08$ ). The analysis shows that indirect learning strategies are not correlated with the attrition time.

From the above analysis, a conclusion can be drawn that the direct learning strategies including Memory Strategies, Cognitive Strategies and Compensation Strategies have significant negative correlations with the attrition time and the indirect learning strategies including Metacognitive Strategies, Affective Strategies and Social Strategies have no significant negative correlations with the attrition time.

The subjects' English learning has been completely stopped for the lack of learning environment since their graduation from junior or senior schools. Nobody could persist in learning English. As a result, what they have already learned began to be forgotten. As time passed on, the subjects forgot more and remembered less. Thus their language proficiency became lower and lower. Language proficiency affects the language learning strategies. The use of learning strategies got worse and worse. The direct learning strategies directly involve the target language. The indirect learning strategies provide indirect support for language learning. So the effect language proficiency has on the direct learning strategies is greater than that language proficiency has on the indirect learning strategies.
TABLE II. CORRELATIONS BETWEEN TIME AND SIX LEARNING STRATEGES

\begin{tabular}{|l|l|l|}
\hline \multicolumn{1}{|c|}{ Strategies } & Pearson Correlation & Sig. (2-tailed) \\
\hline Memory & $-.182(* *)$ & .005 \\
\hline Cognitive & $-.265(* *)$ & .000 \\
\hline Compensation & $-.293(* *)$ & .000 \\
\hline Met acognitive & -.079 & .224 \\
\hline Affect ive & -.099 & .129 \\
\hline Social & -.105 & .108 \\
\hline \multicolumn{2}{|c|}{ a. ${ }^{* *}$ Correlation is significant at the 0.01 level (2-tailed). } \\
b. $*$ Correlation is significant at the 0.05 level (2-tailed).
\end{tabular}

\section{Simple regression analysis}

Correlation analysis demonstrates the relationship between the variables. But it can not be used to determine to what extent independent variable predicts learning strategies achievements. Thus, simple regression analysis is done for this purpose, and the results are shown in the Table 3 . In the Table 3, the attrition time is independent variable, and Memory Strategies, Cognitive Strategies and Compensation Strategies are dependent variables. Three regression equation can be established between the attrition time and three learning strategies: Memory Strategies $=-0.033$ Time + 2.416; Cognitive Strategies $=-0.047$ Time +2.622 ; Compensation Strategies $=-0.067$ Time +2.999 . (Time: the attrition time). Base on the above regression equations, all the scores that the subjects get in Memory Strategies, Cognitive Strategies and Compensation Strategies can be calculated.

TABLE III.

\begin{tabular}{|l|l|c|c|}
\hline \multirow{2}{*}{ Strategies } & & \multicolumn{2}{|c|}{$\begin{array}{c}\text { Unstandardized } \\
\text { Coefficients }\end{array}$} \\
\cline { 3 - 4 } & & B & $\begin{array}{c}\text { Std. } \\
\text { Error }\end{array}$ \\
\hline \multirow{2}{*}{ Memory } & Constant & 2.416 & .066 \\
\cline { 3 - 4 } & Time & -.033 & .012 \\
\hline \multirow{2}{*}{ Cognitive } & Constant & 2.622 & .064 \\
\cline { 2 - 4 } & Time & -.047 & .011 \\
\hline \multirow{2}{*}{ Compensation } & Constant & 2.999 & .080 \\
\cline { 2 - 4 } & Time & -.067 & .014 \\
\hline
\end{tabular}

\section{MAJOR FINDINGS}

Based on the previous studies, the present study investigates the language learning strategies use and whether the attrition time has an influence on the language learning strategies use. The findings of this study are summarized as follows:

In terms of frequency of the use of different categories of learning strategies, Compensation and Metacognitive are reported as being used the most frequently, while Memory strategies are the least frequently used. The subjects, strategies use is at mediu m level. 
As for the relationship between the attrition time and language strategies, the study indicates that the attrition time has significant but negative correlations with Memory Strategies, Cognitive Strategies and Compensation Strategies at the 0.01 level.

With regard to the extent the attrition time can predict the learning strategies achievements, three regression equations are established, which can predict the scores the subjects get in Memory Strategies, Cognitive Strategies and Compensation Strategies.

\section{IMPLICATIONS}

The findings in this study suggest a number of implications for the teaching.

Firstly, raise the learners' awareness about strategy use. In the forms of English courses, lectures and discussions, it is necessary for teachers to explain the strategy use and its importance in learning process and help them grasp the broader applications of language learning strategies. In addition, the strategy training should be inserted into the concrete learning tasks. And the learners learn how to use the language learning strategies during the process of accomplishing the tasks. Learners should be provided chances to discuss and evaluate the strategy use.

Secondly, promote learners autonomy. To avoid the negative influence that attrition time has on the strategies use, the learners must be promoted to become autonomous, especially outside the classroom. Thus they can possess the ability to take change of their own English learning and persist in English learning.

Thirdly, improve the learners' language proficiency. Teachers should take into account the learners' language learning starting stage. At the beginning of learners' college study. Teachers should understand their language learning starting stage and adopt suitable teaching methods and textbooks. The improvement of learners' language proficiency can promote the English learning and the strategies.

Fourthly, the environmental factors in the army should be taken into consideration. Teachers should combine the learners' majors with English learning and make learners realize importance of English in their professions. The examination and graduation systems should be reformed. If learners can't get excellent scores in the exam, they will not be assigned jobs.

\section{REFERENCE}

[1] Oxford, R. Language Learning Strategies: What Every Teacher Should Know [M]. New York:Newburry House Publisher, 1990.

[2] Weltens, Bert. The attrition of foreign-language skills:a literature review[J]. Applied Linguistics, 1987, (8): 22-37.

[3] Tomiyama $\mathrm{M}$. The first stage of second language attrition: A case study of a Japanese returnee $[\mathrm{C}] / /$ Hansen L. Second Language Attrition in Japanese Contexts. New York: Oxford University Press. I 999: 59-79. 